\title{
Analysis of Consumer Perceptions on Food Purchasing During COVID-19 Pandemic in Bangladesh
}

\author{
Most Moriom Khatun ${ }^{1, ~ *, ~ N o o r ~ M d . ~ R a h m a t u l l a h ~}{ }^{2}$, Sharmin Afrin ${ }^{1}$, Fazlul Hoque ${ }^{1}$, \\ Tanjina Afrin ${ }^{1}$, Fatema-tuz-Zohura ${ }^{3}$ \\ ${ }^{1}$ Department of Agribusiness and Marketing, Sher-e-Bangla Agricultural University, Dhaka, Bangladesh \\ ${ }^{2}$ Department of Agricultural Statistics, Sher-e-Bangla Agricultural University, Dhaka, Bangladesh \\ ${ }^{3}$ Department of Agricultural Economics, Sher-e-Bangla Agricultural University, Dhaka, Bangladesh
}

Email address:

moriom@sau.edu.bd (M. M. Khatun)

${ }^{*}$ Corresponding author

\section{To cite this article:}

Most Moriom Khatun, Noor Md. Rahmatullah, Sharmin Afrin, Fazlul Hoque, Tanjina Afrin, Fatema-tuz-Zohura. Analysis of Consumer Perceptions on Food Purchasing During COVID-19 Pandemic in Bangladesh. International Journal of Agricultural Economics. Vol. 5, No. 6, 2020, pp. 243-250. doi: 10.11648/j.ijae.20200506.13

Received: October 13, 2020; Accepted: October 23, 2020; Published: November 4, 2020

\begin{abstract}
COVID-19 pandemic creates a worldwide problematic situation as well as Bangladesh which secures the top ten GDP growths in the last decade. Since this country has an agriculture dominated economy, this pandemic badly affects on the agricultural business sector. However, the significance of the COVID-19 pandemic may vary from different parts of Bangladesh. To visualize those effects on the consumers' points of view, this research has been conducted for measuring the different points of pandemic affects on 10 different agricultural products. A survey has been designed to collect the consumers' perception to buy agricultural food during this pandemic and a total of $200+$ valid data was selected for analysis. Data has been randomly collected from all over the country having a prioritized location with a higher COVID-19 detection rate. Respondents shared their viewpoints on 10 different agricultural products type named as Coarse Rice, finer quality rice, beef \& mutton, poultry \& egg, local fish, exported fish, fruits \& vegetables, cooking oil, spice crops, and imported foods. The data are statistically analyzed to answer three research questions regarding food availability, price hiking, and the government's initiatives to mitigate the impact of this pandemic. It has been found that almost every consumer reports comparatively higher pricing and a lack of agricultural products in the domestic market. All the data are negatively skewed for pricing in terms of any cities in Bangladesh, which means every consumer suffer from the price hiking during this pandemic. It also depicted that the food crisis was more dominated in the capital city rather than the remote local villages, which may happen due to the supply chain disruption of perishable products. However, the government already took some initiatives to mitigate the effect of this pandemic, but more thanthemajority of the respondents are not fully convinced of that. An interesting finding is that the crisis issue is not significantly dependent on any consumers' demographic data, which means every category of consumers already more or less affected by the pandemic.
\end{abstract}

Keywords: Agribusiness, Food Security, Consumer Perception, COVID-19, Agricultural Economics

\section{Introduction}

COVID-19 is becoming the top challenge all over the globe in every economical sector especially in food security and agribusiness [1, 2]. Bangladesh, the most densely populated country, has also been affected badly due to this pandemic. Currently, this country's agriculture economy contributes $\$ 126.58$ million USD in the GDP of the year 2019 which increases $26 \%$ in the last 10 years [3]. The agriculture sector employs $43 \%$ of the country's population directly or indirectly, which is more than 70 million and equivalent to two times of Canadian total population. This large sector of Bangladesh suffers due to the COVID-19 pandemic.

This paper assesses that the Impact of the COVID-19 
pandemic on agribusiness in Bangladesh from a direct survey of local consumers. However, the significance of the COVID-19 pandemic varied from different parts of Bangladesh, which has been depicted in this paper. Respondents submitted their perception from different parts of this country, where the major portion $45 \%$ came from the Dhaka division which is almost equal to the positive COVID-19 infected patient (67\%). Respondents shared their viewpoints from different issues such as pricing, availability, food security, government initiatives, etc. These above points of view are measured on 10 different agricultural products type named as Coarse Rice, finer quality rice, beef \& mutton, poultry \& egg, local fish, exported fish, fruits \& vegetables, cooking oil, spice crops, and imported foods. This paper aims to visualize the pandemic impact on Bangladeshi consumers in terms of food pricing and availability as well as the government initiatives for controlling the local food market.

After analyzing the survey data, it has been found that prices are increased for every food except egg and vegetables. Almost every product is available in the local market but the scenario is opposite in the capital and some of the divisional districts. It also found that people of Bangladesh are very conservative about food exporting and security issues because maximum respondents want to stop food exporting for handling post-pandemic local food security issues. It is needless to say that government initiatives didn't work expectedly to handle the crisis in the agricultural economy during this pandemic; they should have amalgamated with all respective directorates for a combined fight against COVID-19 in the Bangladeshi agribusiness sector.

\section{Literature Review}

COVID-19 has a drastic impact on food and agriculture sector all over the world [4, 5]. Due to the lockdown in almost every country in the world, transportation and food supply chain is disrupted badly which create negative effect on the pricing and availability of agricultural products [6, 7]. The impact of COVID-19 in agriculture and food sector of Canada has been described by Goddard [8]. She categorized the impacts in two main categories where the first one is on the consumer perceptions in food purchase and another one is on the impact of supply chain where the individuals and employers related to food service are involved.

The supply chain has also badly disrupted at Bangladeshi domestic food supply [9] which create an economical crisis to the farmers with the lower price issue of agricultural food due to shortage of labor in product supply and buyer in the market. The supply chain disruption also affects the food security and availability to ensure physical access to food $[10,11]$. Not only the food sector but also the forestry and fisheries are also affected in this pandemic [12].

Food system needs to be redesigned in the future to overcome this pandemic effect [13]. It should be mentioned that online market place became popular in all over the world [14] including Bangladesh $[15,16]$ which can make a positive role during the pandemic. Consumers are willing to pay any cost for food reserve to address their daily demands in this pandemic [17]. However, none of them assessing the current market scenario of agricultural products in Bangladesh which is one of the curtail part of a consumer daily activity.

\section{Methodology}

This research has been followed by the quantitative and explorative approach to observe the consumer perception on the agribusiness sector in Bangladesh during this pandemic. We have selected all over the country for data collection because every portion might have different impact. However, the capital city was considered the prioritized one for respondents because it has the maximum COVID-19 patients. The dependent variables were utilizing on a Likert scale of 1, 2, 3, 4, and 5 represented as strongly agree, agree, neutral, disagree, and strongly disagree respectively.

\subsection{Research Questions}

To assess the impact of COVID-19 pandemics on the food and agricultural products marketing in Bangladesh, three different research questions were selected.

RQ1: Are the food similarly available in all over the country during this pandemic?

1. Are foods similarly available in Capital and other places?

2. Are foods similarly available in divisional states and other districts?

RQ2: Are the food price remains same in all over the country during this pandemic?

1. Are pricing remains same in Capital and other places?

2. Are the pricing remains same in divisional states and other districts?

RQ3: Are the government initiatives convince the consumers regarding the food issue during this pandemic.

All the above questions need to be answered from the consumers' point of views, because they are the first line collaborator of the agricultural business sector.

\subsection{Dataset}

A survey has been designed to retrieve the consumer perception on food purchase in Bangladesh. Total 205 data are collected from randomly picked various consumers in Bangladesh during the COVID-19 pandemic period. An overview of the dataset description is listed at Table 1. 
Table 1. Overview of Dataset Description.

\begin{tabular}{|c|c|c|c|c|c|c|}
\hline & & \multicolumn{5}{|c|}{ Gender } \\
\hline & & Male & Female & Total & Total (\%) & Cumulative \\
\hline \multirow{7}{*}{$\begin{array}{l}\text { Division Wise } \\
\text { Distribution }\end{array}$} & Barisal & 3 & 8 & 11 & $5.4 \%$ & $5 \%$ \\
\hline & Chattagram & 12 & 2 & 14 & $6.8 \%$ & $12 \%$ \\
\hline & Dhaka & 57 & 50 & 107 & $52.2 \%$ & $64 \%$ \\
\hline & Khulna & 7 & 16 & 23 & $11.2 \%$ & $76 \%$ \\
\hline & Mymensing & 5 & 6 & 11 & $5.4 \%$ & $81 \%$ \\
\hline & Rajshahi & 8 & 4 & 12 & $5.9 \%$ & $87 \%$ \\
\hline & Sylhet & 4 & 10 & 14 & $6.8 \%$ & $100 \%$ \\
\hline \multirow{2}{*}{ Capital City } & Outside & 63 & 61 & 124 & $60.5 \%$ & $60 \%$ \\
\hline & Inside & 44 & 37 & 81 & $39.5 \%$ & $100 \%$ \\
\hline \multirow{2}{*}{ Divisional City } & Outside & 49 & 58 & 107 & $52.2 \%$ & $52 \%$ \\
\hline & Inside & 58 & 40 & 98 & $47.8 \%$ & $100 \%$ \\
\hline \multirow{2}{*}{$\begin{array}{l}\text { Purchase from Local } \\
\text { Market }\end{array}$} & Yes & 89 & 61 & 150 & $73.2 \%$ & $73 \%$ \\
\hline & No & 18 & 37 & 55 & $26.8 \%$ & $100 \%$ \\
\hline \multirow{3}{*}{ Age } & $<20$ & 7 & 13 & 20 & $9.8 \%$ & $10 \%$ \\
\hline & $30-39$ & 19 & 17 & 36 & $17.6 \%$ & $58 \%$ \\
\hline & $>=40$ & 48 & 39 & 87 & $42.4 \%$ & $100 \%$ \\
\hline \multirow{4}{*}{$\begin{array}{l}\text { Educational } \\
\text { Qualification }\end{array}$} & Primary & 7 & 5 & 12 & $5.9 \%$ & $6 \%$ \\
\hline & High School & 3 & 10 & 13 & $6.3 \%$ & $12 \%$ \\
\hline & College & 11 & 4 & 15 & $7.3 \%$ & $20 \%$ \\
\hline & University & 86 & 79 & 165 & $80.5 \%$ & $100 \%$ \\
\hline \multirow{6}{*}{ Occupation } & Business & 17 & 5 & 22 & $10.7 \%$ & $11 \%$ \\
\hline & Student & 12 & 18 & 30 & $14.6 \%$ & $25 \%$ \\
\hline & Private Job & 28 & 19 & 47 & $22.9 \%$ & $48 \%$ \\
\hline & Public Job & 20 & 27 & 47 & $22.9 \%$ & $71 \%$ \\
\hline & Others & 20 & 16 & 36 & $17.6 \%$ & $89 \%$ \\
\hline & Unemployed & 10 & 12 & 22 & $10.7 \%$ & $100 \%$ \\
\hline
\end{tabular}

\section{Results and Discussion}

A survey has been conducted on the food consumers on 10 different categories of food which are frequently purchased by the Bangladeshi people. Those food category lists with the corresponding acronyms which are used to measure the consumer perception are given at Table 2 .

Table 2. Food category with item code.

\begin{tabular}{lll}
\hline Serial & Code & Food Category Name \\
\hline 1 & CR & Coarse Rice \\
2 & FR & Finer Quality Rice \\
3 & BM & Beef \& Mutton \\
4 & PE & Poultry \& Egg \\
5 & LF & Local Fish \\
6 & EF & Exported Fish (Shrimp, Crabs, Dry fish) \\
7 & IF & Imported Food (Frozen \& Imported Fish, Frozen Meat, Processed food, etc.) \\
8 & FV & Fruits and Vegetables (Seasonal fruits, Potato, Tomato, Cucumber, Chili, etc) \\
9 & OL & Oil (Soybean, Mustard, Sunflower, etc.) \\
10 & SP & Spice Crop (Onion, Garlic, Ginger, etc.) \\
\hline
\end{tabular}

\subsection{Effect of Food Availability during thePandemic}

The answer of this question has been derived by consumer perception on food availability issue, which comes from an independent variable of our survey sheet. That statement is "Products are not available enough in market during COVID-19". Consumers rated their perception on the 5 Likert scales where 1 for strongly disagree to 5 for strongly agree. The first research question is derived from two different sub questions on the comparative analysis of food availability in various districts with the country's capital and divisional city accordingly.

The first sub question of RQ1 is denoted as "are the food similarly available in the capital and other local cities in Bangladesh"? The answers of the respondents are analysis and the results are depicted at Table 3. According to that table, it has been clearly shown that all the products are less available in the capital city except imported food (IF). Because imported food received or stored to warehouses in capital which cannot be distributed due to pandemic supply chain disruption. Among all foods, rice faced highest unavailability in the capital having value of mean, mode, std, skewness and kurtosis are 2.69, 2, 1.15, 0.69 and -0.35 respectively. The minimum skewed and mode values are less that -0.5 and 4 respectively for imported and exported food. That means almost every consumers in the capital are convinced with the availability of imported and exported 
food. But they are not satisfied enough on the availability issue with other foods during this pandemic.

Table 3. Consumer perceptions on food availability in the capital and other local markets respectively.

\begin{tabular}{|c|c|c|c|c|c|c|c|c|}
\hline Product & Location & Mean & Median & Mode & Std. Dev. & Variance & Skewness & Kurtosis \\
\hline \multirow{4}{*}{ CR } & Capital & 2.69 & 2 & 2 & 1.15 & 1.32 & 0.69 & -0.35 \\
\hline & Others & 2.85 & 3 & 2 & 1.27 & 1.62 & 0.45 & -0.93 \\
\hline & Diff. & -0.16 & -1 & 0 & -0.13 & -0.30 & 0.24 & 0.58 \\
\hline & Capital & 2.79 & 2 & 2 & 1.19 & 1.42 & 0.56 & -0.75 \\
\hline \multirow[t]{3}{*}{ FR } & Others & 2.95 & 3 & 2 & 1.29 & 1.67 & 0.32 & -1.09 \\
\hline & Diff. & -0.16 & -1 & 0 & -0.10 & -0.25 & 0.23 & 0.33 \\
\hline & Capital & 2.85 & 3 & 2 & 1.09 & 1.18 & 0.18 & -1.03 \\
\hline \multirow[t]{3}{*}{$\mathrm{BM}$} & Others & 3.00 & 3 & 3 & 1.10 & 1.22 & 0.11 & -0.77 \\
\hline & Diff. & -0.15 & 0 & -1 & -0.02 & -0.04 & 0.07 & -0.27 \\
\hline & Capital & 2.73 & 2 & 2 & 1.10 & 1.20 & 0.45 & -0.75 \\
\hline \multirow[t]{3}{*}{ PE } & Others & 2.81 & 2 & 2 & 1.15 & 1.31 & 0.52 & -0.76 \\
\hline & Diff. & -0.08 & 0 & 0 & -0.05 & -0.11 & -0.07 & 0.01 \\
\hline & Capital & 3.05 & 3 & 4 & 1.14 & 1.30 & -0.10 & -0.93 \\
\hline \multirow[t]{3}{*}{ LF } & Others & 3.06 & 3 & 2 & 1.15 & 1.31 & 0.10 & -0.95 \\
\hline & Diff. & -0.02 & 0 & 2 & -0.01 & -0.02 & -0.20 & 0.02 \\
\hline & Capital & 3.57 & 4 & 4 & 1.14 & 1.30 & -0.59 & -0.31 \\
\hline \multirow[t]{3}{*}{$\mathrm{EF}$} & Others & 3.46 & 3 & 3 & 1.14 & 1.31 & -0.11 & -1.08 \\
\hline & Diff. & 0.11 & 1 & 1 & 0.00 & -0.01 & -0.47 & 0.76 \\
\hline & Capital & 3.83 & 4 & 4 & 0.97 & 0.94 & -0.73 & 0.39 \\
\hline \multirow[t]{3}{*}{ IF } & Others & 3.62 & 4 & 4 & 1.10 & 1.21 & -0.31 & -0.94 \\
\hline & Diff. & 0.21 & 0 & 0 & -0.13 & -0.27 & -0.42 & 1.33 \\
\hline & Capital & 3.01 & 3 & 2 & 1.09 & 1.19 & 0.09 & -0.84 \\
\hline \multirow[t]{3}{*}{$\mathrm{FV}$} & Others & 2.97 & 3 & 2 & 1.18 & 1.38 & 0.19 & -0.90 \\
\hline & Diff. & 0.04 & 0 & 0 & -0.09 & -0.19 & -0.09 & 0.06 \\
\hline & Capital & 2.98 & 3 & 2 & 1.18 & 1.40 & 0.33 & -0.83 \\
\hline \multirow[t]{3}{*}{$\mathrm{OL}$} & Others & 3.15 & 3 & 3 & 1.17 & 1.38 & 0.14 & -0.96 \\
\hline & Diff. & -0.17 & 0 & -1 & 0.01 & 0.02 & 0.19 & 0.12 \\
\hline & Capital & 3.20 & 3 & 2 & 1.22 & 1.49 & 0.12 & -1.16 \\
\hline \multirow{2}{*}{ SP } & Others & 3.38 & 3 & 3 & 1.19 & 1.41 & -0.03 & -1.16 \\
\hline & Diff. & -0.18 & 0 & -1 & 0.03 & 0.08 & 0.15 & 0.00 \\
\hline
\end{tabular}

The second sub question of Research Question 1 is designed for the comparative study on food availability in divisional city and other local cities in Bangladesh. The analysis of respondents data are presented at Table 4. According to that table, there are not significantly difference of food availability issue between divisional cities and local districts. The maximum and minimum skewness are 0.61 and -0.57 for coarse rice (CR) and imported food (IF) respectively. That means rice is not transported smoothly to the large divisional cities from the remote warehouse, so the data are right skewed. The minimum of Skewness values are vice versa for imported food, because that type of food warehouse basically located at Dhaka and Chottogram, two largest divisional cities in Bangladesh. Interestingly the differences of all the data in Table 4 are very small in numbers with the all time zero in mode and median value.

Table 4. Consumer perceptions on food availability in divisional cities and other local markets respectively.

\begin{tabular}{|c|c|c|c|c|c|c|c|c|}
\hline Product & Location & Mean & Median & Mode & Std. Dev. & Variance & Skewness & Kurtosis \\
\hline \multirow{3}{*}{$\mathrm{CR}$} & Division & 2.79 & 2 & 2 & 1.20 & 1.45 & 0.61 & -0.65 \\
\hline & Others & 2.83 & 2 & 2 & 1.22 & 1.49 & 0.57 & -0.78 \\
\hline & Diff. & -0.05 & 0 & 0 & -0.02 & -0.04 & 0.03 & 0.14 \\
\hline \multirow{3}{*}{ FR } & Division & 2.86 & 2 & 2 & 1.22 & 1.48 & 0.49 & -0.90 \\
\hline & Others & 2.91 & 2 & 2 & 1.24 & 1.55 & 0.47 & -1.01 \\
\hline & Diff. & -0.05 & 0 & 0 & -0.03 & -0.06 & 0.02 & 0.11 \\
\hline \multirow{2}{*}{$\mathrm{BM}$} & Division & 2.86 & 3 & 2 & 1.06 & 1.13 & 0.19 & -0.92 \\
\hline & Diff. & -0.06 & 0 & 0 & -0.02 & -0.04 & 0.02 & 0.03 \\
\hline \multirow{3}{*}{ PE } & Division & 2.72 & 2 & 2 & 1.09 & 1.19 & 0.47 & -0.76 \\
\hline & Others & 2.80 & 2 & 2 & 1.13 & 1.27 & 0.45 & -0.87 \\
\hline & Diff. & -0.07 & 0 & 0 & -0.04 & -0.08 & 0.03 & 0.11 \\
\hline \multirow{3}{*}{$\mathrm{LF}$} & Division & 3.05 & 3 & 4 & 1.13 & 1.29 & -0.06 & -0.92 \\
\hline & Others & 3.06 & 3 & 4 & 1.15 & 1.32 & -0.05 & -0.94 \\
\hline & Diff. & -0.01 & 0 & 0 & -0.01 & -0.03 & -0.01 & 0.03 \\
\hline \multirow{2}{*}{$\mathrm{EF}$} & Division & 3.53 & 4 & 4 & 1.14 & 1.30 & -0.44 & -0.59 \\
\hline & Diff. & -0.03 & 0 & 0 & -0.02 & -0.06 & 0.03 & 0.03 \\
\hline \multirow{2}{*}{ IF } & Division & 3.77 & 4 & 4 & 1.00 & 1.01 & -0.57 & -0.16 \\
\hline & Others & 3.77 & 4 & 4 & 1.02 & 1.03 & -0.55 & -0.30 \\
\hline
\end{tabular}




\begin{tabular}{lllllllll}
\hline Product & Location & Mean & Median & Mode & Std. Dev. & Variance & Skewness & Kurtosis \\
\hline \multirow{4}{*}{ FV } & Diff. & -0.01 & 0 & 0 & -0.01 & -0.02 & -0.02 & 0.14 \\
& Division & 2.98 & 3 & 2 & 1.09 & 1.20 & 0.09 & -0.82 \\
& Others & 3.02 & 3 & 2 & 1.11 & 1.24 & 0.05 & -0.86 \\
\multirow{5}{*}{ OL } & Diff. & -0.04 & 0 & 0 & -0.02 & -0.04 & 0.04 & 0.04 \\
& Division & 2.98 & 3 & 2 & 1.16 & 1.34 & 0.28 & -0.82 \\
& Others & 3.06 & 3 & 2 & 1.18 & 1.39 & 0.24 & -0.91 \\
\multirow{5}{*}{ SP } & Diff. & -0.08 & 0 & 0 & -0.02 & -0.05 & 0.05 & 0.10 \\
& Division & 3.23 & 3 & 2 & 1.18 & 1.40 & 0.10 & -1.09 \\
& Others & 3.31 & 3 & 2 & 1.20 & 1.44 & 0.03 & -1.18 \\
\hline
\end{tabular}

\subsection{Effect of Food Pricing in the Local Market During the Pandemic}

The second research question is related with the pricing issue of agricultural goods basically foods available in local market. To answer this question, a specific statement has been selected for collect the feedback from the consumers, which is "Price Increase a lot during COVID-19". Consumers rated their perception on the five Likert scales where 1 for strongly disagree to 5 for strongly agree. The RQ2 is divided into two sub questions where the first one is concern with the pricing issue of the capital and other local markets. Another one is concern with the pricing issue of the divisional cities (8 divisional cities in Bangladesh) and other local markets.

The first sub question of RQ2 is stated as "Are the pricing remains same in Capital and other places?" The analyses of the respondents' data are presented at Table 5. According to that table, the average respondents' perception on prices in the capital CR, FR, BM, PE, LF, EF, IF, FV, OL, and SP are 3.94,
$4.21,4.11,3.40,3.78,4.09,4.05,3.95,3.84$ and 4.14 respectively. On the other hand the average price respondents for other local markets are 3.94, 4.26, 3.90, 3.28, 3.52, 3.59, $3.97,3.40,3.71$ and 4.06 accordingly. The median values are always above 3 , which indicate that the majority of consumers perceived that the prices of agricultural goods are increased during the pandemic period. The maximum price increment is perceived in finer quality rice (FR) containing mean $(4.21 \&$ 4.26) and median (4 \& 5) for capital and other cities respectively. This means every people either the capital or other local cities suffer due to the price hike of rice. Furthermore the price data are also huge left skewed with the value of -1.30 and -1.51 for capital and other local markets respectively. It should be reported that every data show negative skewness for all food prices in both the capital and other local city markets. That means all the agricultural goods are overpriced during the pandemic time phases in Bangladesh, which make the lifestyle difficult for the common people.

Table 5. Consumer perceptions on food availability in the capital and other local markets respectively.

\begin{tabular}{|c|c|c|c|c|c|c|c|c|}
\hline Product & Location & Mean & Median & Mode & Std. Dev. & Variance & Skewness & Kurtosis \\
\hline \multirow{3}{*}{ CR } & Capital & 3.94 & 4 & 4 & 0.99 & 0.98 & -0.82 & 0.42 \\
\hline & Others & 3.94 & 4 & 4 & 0.97 & 0.93 & -0.99 & 0.86 \\
\hline & Diff. & 0.00 & 0 & 0 & 0.03 & 0.05 & 0.17 & -0.45 \\
\hline \multirow{3}{*}{ FR } & Capital & 4.21 & 4 & 4 & 0.85 & 0.72 & -1.30 & 2.26 \\
\hline & Others & 4.26 & 4 & 5 & 0.94 & 0.88 & -1.51 & 2.39 \\
\hline & Diff. & -0.05 & 0 & -1 & -0.09 & -0.16 & 0.20 & -0.13 \\
\hline \multirow{2}{*}{ BM } & Capital & 4.11 & 4 & 5 & 0.97 & 0.95 & -0.64 & -0.85 \\
\hline & Diff. & 0.21 & 0 & 0 & -0.09 & -0.18 & 0.03 & -0.41 \\
\hline \multirow{3}{*}{ PE } & Capital & 3.40 & 3 & 2 & 1.20 & 1.44 & -0.06 & -1.29 \\
\hline & Others & 3.28 & 3 & 4 & 1.32 & 1.73 & -0.25 & -1.11 \\
\hline & Diff. & 0.11 & 0 & -2 & -0.12 & -0.29 & 0.20 & -0.18 \\
\hline \multirow{3}{*}{$\mathrm{LF}$} & Capital & 3.78 & 4 & 4 & 0.97 & 0.95 & -0.28 & -0.92 \\
\hline & Others & 3.52 & 4 & 4 & 1.06 & 1.11 & -0.40 & -0.35 \\
\hline & Diff. & 0.26 & 0 & 0 & -0.08 & -0.16 & 0.12 & -0.57 \\
\hline \multirow[t]{2}{*}{$\mathrm{EF}$} & Others & 3.59 & 4 & 4 & 1.20 & 1.45 & -0.64 & -0.49 \\
\hline & Diff. & 0.50 & 0 & 1 & -0.14 & -0.32 & -0.30 & 0.39 \\
\hline \multirow{3}{*}{ IF } & Capital & 4.05 & 4 & 5 & 0.97 & 0.95 & -0.77 & -0.39 \\
\hline & Others & 3.97 & 4 & 4 & 1.00 & 1.01 & -0.82 & 0.08 \\
\hline & Diff. & 0.08 & 0 & 1 & -0.03 & -0.06 & 0.05 & -0.46 \\
\hline \multirow{3}{*}{$\mathrm{FV}$} & Capital & 3.95 & 4 & 4 & 1.02 & 1.05 & -0.83 & -0.06 \\
\hline & Others & 3.40 & 4 & 4 & 1.32 & 1.74 & -0.42 & -1.05 \\
\hline & Diff. & 0.56 & 0 & 0 & -0.29 & -0.69 & -0.41 & 0.99 \\
\hline \multirow{3}{*}{$\mathrm{OL}$} & Capital & 3.84 & 4 & 4 & 0.98 & 0.96 & -0.57 & -0.25 \\
\hline & Others & 3.71 & 4 & 4 & 1.04 & 1.09 & -0.40 & -0.64 \\
\hline & Diff. & 0.13 & 0 & 0 & -0.06 & -0.12 & -0.17 & 0.39 \\
\hline \multirow{3}{*}{ SP } & Capital & 4.15 & 4 & 4 & 0.88 & 0.78 & -0.97 & 0.42 \\
\hline & Others & 4.06 & 4 & 5 & 0.99 & 0.97 & -0.80 & -0.39 \\
\hline & Diff. & 0.08 & 0 & -1 & -0.10 & -0.19 & -0.17 & 0.80 \\
\hline
\end{tabular}


The second sub question of RQ2 is related with the pricing issue compare to divisional cities and other district level markets. The actual research sub question can be selected as "are the pricing remains same in the divisional state and other district"? The statistical analysis of the respondents data for answering this sub question are presented at Table 6. The higher the value is more likely perceived of the price increment. According to the table, the average respondents' perception on prices in divisional cities for $\mathrm{CR}, \mathrm{FR}, \mathrm{BM}, \mathrm{PE}$, LF, EF, IF, FV, OL, and SP are 3.96, 4.23, 4.03, 3.38, 3.71,
$3.98,4.02,3.84,3.85$ and 4.14 respectively. On the other hand the average perceptions by other district level local markets are $3.97,4.27,4.05,3.39,3.76,3.94,4.01,3.83,3.86$, and 4.14 accordingly. According to the Table 6, finer rice has the highest skewness -1.52 with mean, mode and kurtosis value $4.27,5$ and 2.44 accordingly. This indicates that price hiking of rice has the maximum impact on consumers. However, the level of price hiking between the divisional city and other district base local market are quite similar.

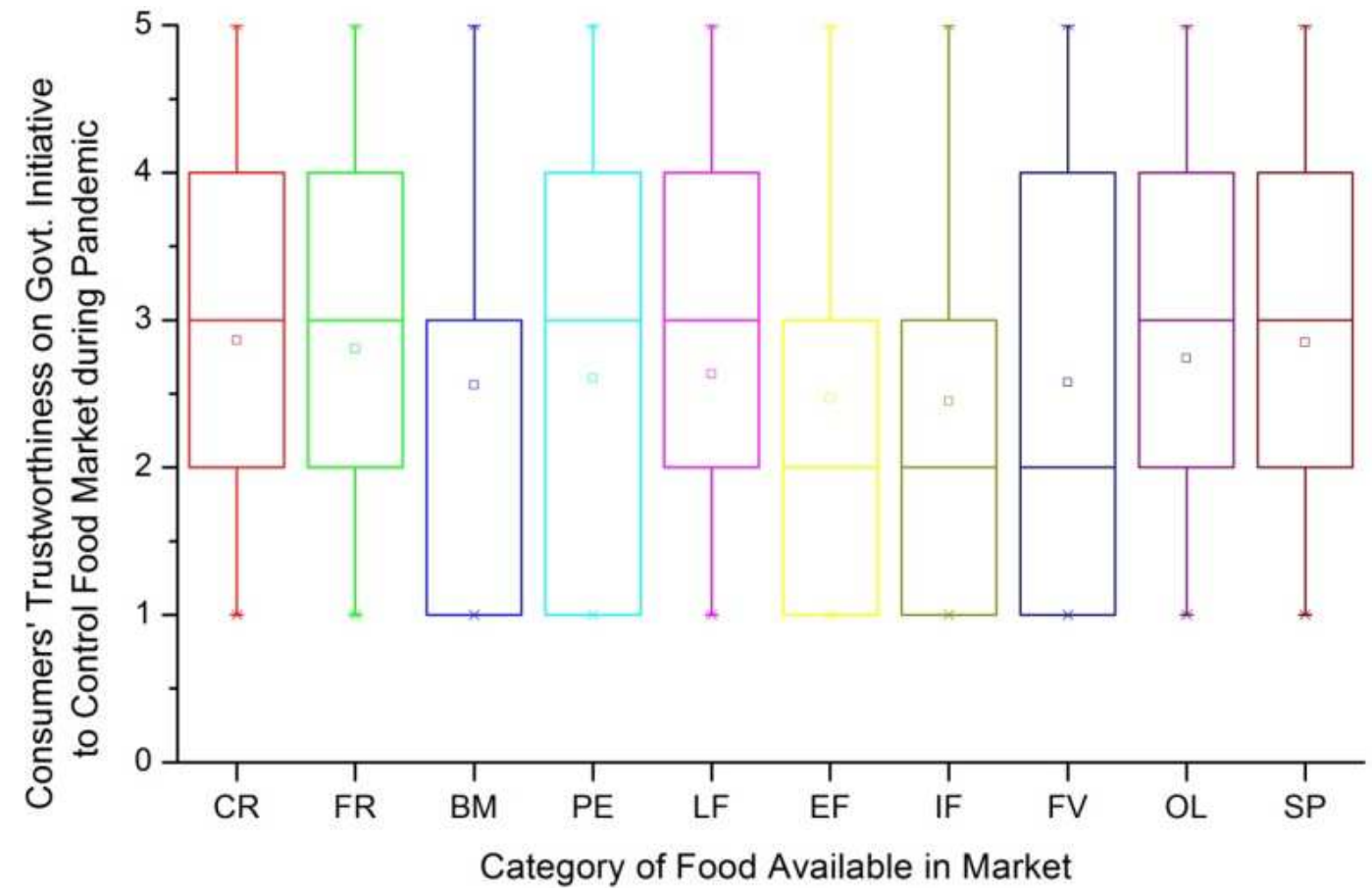

Figure 1. Category of Food Available in Market vs Consumers' Trustworthiness on Govt. Initiative.

Table 6. Consumer perceptions on food availability in the capital and other local markets respectively.

\begin{tabular}{|c|c|c|c|c|c|c|c|c|}
\hline Product & Location & Mean & Median & Mode & Std. Dev. & Variance & Skewness & Kurtosis \\
\hline \multirow{3}{*}{ CR } & Division & 3.96 & 4 & 4 & 0.97 & 0.95 & -0.81 & 0.37 \\
\hline & Others & 3.97 & 4 & 4 & 0.98 & 0.96 & -1.02 & 0.94 \\
\hline & Diff. & -0.01 & 0 & 0 & -0.01 & -0.01 & 0.21 & -0.56 \\
\hline \multirow{3}{*}{ FR } & Division & 4.23 & 4 & 4 & 0.85 & 0.72 & -1.30 & 2.07 \\
\hline & Others & 4.27 & 4 & 5 & 0.95 & 0.90 & -1.52 & 2.44 \\
\hline & Diff. & -0.03 & 0 & -1 & -0.10 & -0.19 & 0.21 & -0.37 \\
\hline \multirow{3}{*}{$\mathrm{BM}$} & Division & 4.03 & 4 & 4 & 1.00 & 1.00 & -0.57 & -0.91 \\
\hline & Others & 4.05 & 4 & 4 & 1.06 & 1.13 & -0.75 & -0.26 \\
\hline & Diff. & -0.02 & 0 & 0 & -0.06 & -0.13 & 0.18 & -0.65 \\
\hline \multirow{3}{*}{ PE } & Division & 3.38 & 3 & 2 & 1.25 & 1.56 & -0.14 & -1.19 \\
\hline & Others & 3.39 & 3 & 2 & 1.29 & 1.68 & -0.25 & -1.09 \\
\hline & Diff. & -0.01 & 0 & 0 & -0.05 & -0.12 & 0.11 & -0.10 \\
\hline \multirow{3}{*}{ LF } & Division & 3.71 & 4 & 4 & 1.03 & 1.05 & -0.33 & -0.75 \\
\hline & Others & 3.76 & 4 & 4 & 1.03 & 1.06 & -0.43 & -0.23 \\
\hline & Diff. & -0.05 & 0 & 0 & -0.01 & -0.01 & 0.10 & -0.52 \\
\hline \multirow{3}{*}{$\mathrm{EF}$} & Division & 3.98 & 4 & 5 & 1.12 & 1.26 & -0.94 & 0.01 \\
\hline & Others & 3.94 & 4 & 5 & 1.20 & 1.43 & -0.61 & -0.52 \\
\hline & Diff. & 0.03 & 0 & 0 & -0.07 & -0.17 & -0.33 & 0.52 \\
\hline \multirow{3}{*}{ IF } & Division & 4.02 & 4 & 5 & 0.96 & 0.93 & -0.68 & -0.51 \\
\hline & Others & 4.01 & 4 & 5 & 1.02 & 1.04 & -0.89 & 0.20 \\
\hline & Diff. & 0.01 & 0 & 0 & -0.06 & -0.11 & 0.21 & -0.71 \\
\hline \multirow{3}{*}{ FV } & Division & 3.84 & 4 & 4 & 1.11 & 1.23 & -0.73 & -0.45 \\
\hline & Others & 3.83 & 4 & 4 & 1.32 & 1.73 & -0.47 & -0.96 \\
\hline & Diff. & 0.01 & 0 & 0 & -0.21 & -0.50 & -0.26 & 0.51 \\
\hline
\end{tabular}




\begin{tabular}{|c|c|c|c|c|c|c|c|c|}
\hline Product & Location & Mean & Median & Mode & Std. Dev. & Variance & Skewness & Kurtosis \\
\hline \multirow{3}{*}{$\mathrm{OL}$} & Division & 3.85 & 4 & 4 & 0.98 & 0.96 & -0.56 & -0.32 \\
\hline & Others & 3.86 & 4 & 4 & 1.05 & 1.11 & -0.37 & -0.65 \\
\hline & Diff. & -0.02 & 0 & 0 & -0.07 & -0.15 & -0.19 & 0.33 \\
\hline \multirow{3}{*}{ SP } & Division & 4.14 & 4 & 4 & 0.89 & 0.78 & -0.92 & 0.25 \\
\hline & Others & 4.14 & 4 & 4 & 1.00 & 1.00 & -0.81 & -0.41 \\
\hline & Diff. & 0.00 & 0 & 0 & -0.11 & -0.21 & -0.11 & 0.66 \\
\hline
\end{tabular}

\subsection{Consumers Perceptions on the Government Initiatives During the Pandemic}

The third research question is related to the government initiative for controlling the market of agricultural foods, which ensures consumers viewpoints on market during the pandemic situation. The independent variable of "Govt. Initiatives" linked with the questionnaire statement "Government attempts work perfectly to stable products price during pandemic". Consumers' respondents' data are analyzed and depicted by box whisker plot in Figure 1. Food categories and consumers' trustworthiness on govt. initiative to control food market are graphed as $\mathrm{X}$ axis and $\mathrm{Y}$ axis respectively. Among the all ten food categories exported fish, imported food, fruits and vegetables have mean values 2 and lower quartiles are below 2 . That means those three category food markets are well managed by government initiatives.

\section{Conclusion}

This paper presents an analysis of consumer perceptions of food purchasing during the COVID-19 pandemic in Bangladesh. Consumers all over the world are really affected due to purchasing basic goods e.g. food because of unavailability, and price hiking. Like others, Bangladeshi consumers also suffer during this situation, but the level is not catastrophic because of the high volume of locally grown foods. This research conducted a survey on all over the country to collect the actual consumer perceptions on the food market. The data analysis shows that foods are not equally available in the capital city and other local markets. It may happen due to the supply chain disruption from the farmers to consumers. It also found that almost every consumer expects extra initiatives by a government authority on the agriculture and food sectors. Building a sustainable supply chain and extra concern on agricultural production may overcome the food security problem in the local consumers. This paper recommends that authority should take precise steps to handle local market for food pricing and availability issue. Country like Bangladesh which has highly fertile arable land and skilled agriculturist should participate in global food security and hunger mitigation during this COVID-19 pandemic.

\section{Acknowledgements}

Authors would like to express their acknowledgements to the Faculty of Agribusiness Management, Sher-e-Bangla Agricultural University for supporting this research.

\section{References}

[1] S. Baker, N. Bloom, S. Davis, and S. Terry, "COVID-Induced Economic Uncertainty," Natl. Bur. Econ. Res., 2020, doi: $10.3386 / \mathrm{w} 26983$

[2] D. Laborde, W. Martin, J. Swinnen, and R. Vos, "COVID-19 risks to global food security," Science, vol. 369, no. 6503, pp. 500-502, 2020, doi: 10.1126/science.abc4765.

[3] Trading Economics, "Bangladesh GDP From Agriculture," 2020.

https://tradingeconomics.com/bangladesh/gdp-from-agricultur e (accessed Oct. 09, 2020).

[4] N. Khan, B. N. Siddiqui, N. Khan, and N. Ullah, "Drastic impacts of COVID-19 on food, agriculture and economy," Pure Appl. Biol., vol. 10, no. 1, pp. 62-68, 2020.

[5] R. Siche, "What is the impact of COVID-19 disease on agriculture?," Sci. Agropecu., vol. 11, no. 1, pp. 3-9, 2020, doi: 10.17268/sci.agropecu.2020.01.00.

[6] J. E. Hobbs, "Food supply chains during the COVID-19 pandemic," Can. J. Agric. Econ., vol. 68, no. 2, pp. 171-176, 2020, doi: 10.1111/cjag.12237.

[7] R. S. Gray, "Agriculture, transportation, and the COVID-19 crisis,” Can. J. Agric. Econ., vol. 68, no. 2, pp. 239-243, 2020, doi: 10.1111/cjag.12235.

[8] E. Goddard, "The impact of COVID-19 on food retail and food service in Canada: Preliminary assessment," Can. J. Agric. Econ., vol. 68, no. 2, pp. 157-161, 2020, doi: 10.1111/cjag. 12243 .

[9] A. Al Zabir, A. Mahmud, M. A. Islam, S. C. Antor, F. Yasmin, and A. Dasgupta, "COVID-19 and Food Supply in Bangladesh: A Review,” SSRN Electron. J., no. May, pp. 1-16, 2020, doi: 10.2139/ssrn.3595967.

[10] D. Dev and K. Kabir, "COVID-19 and Food Security in Bangladesh: A Chance to Look Back at What Is Done and What Can Be Done," J. Agric. Food Syst. Community Dev., pp. 1-3, 2020, doi: 10.5304/jafscd.2020.094.008.

[11] S. Devereux, C. Béné, and J. Hoddinott, "Conceptualising COVID-19's impacts on household food security," Food Secur., vol. 12, no. 4, pp. 769-772, 2020, doi: 10.1007/s12571-020-01085-0.

[12] J. Greenville, H. Mcgilvray, L. Y. Cao, and J. Fell, "Impacts of COVID-19 on Australian agriculture, forestry and fisheries trade," $2020 . \quad$ [Online]. Available: https://www.agriculture.gov.au/abares/research-topics/trade/im pacts-of-COVID-19-on-Australian-trade.

[13] A. P. Ker, "Risk management in Canada's agricultural sector in light of COVID-19," Can. J. Agric. Econ., vol. 68, no. 2, pp. 251-258, 2020, doi: 10.1111/cjag.12232. 
[14] B. A. Bhat et al., "A Study on COVID-19 lockdown impact on food, agriculture, fisheries and precautionary measures to avoid COVID-19 contamination," Galore Int. J. Appl. Sci. Humanit., vol. 4, no. 2 , pp. $8-18,2020$.

[15] M. M. Khatun, N. M. Rahamatullah, T. Afrin, S. Islam, and M. Rahman, "Consumer Perception of Online Marketplace in Bangladesh: An Empirical Study on Dhaka City," Asian Bus. Rev., vol. 10, no. 2, pp. 115-120, 2020, doi: 10.18034/abr.v10i2.473.
[16] S. Chowhan and S. R. Ghosh, "Role of ICT on Agriculture and Its Future Scope in Bangladesh," J. Sci. Res. Reports, vol. 26, no. 5, pp. 20-35, 2020, doi: 10.9734/jsrr/2020/v26i530257.

[17] E. Wang, N. An, Z. Gao, E. Kiprop, and X. Geng, "Consumer food stockpiling behavior and willingness to pay for food reserves in COVID-19," Food Secur., vol. 12, no. 4, pp. 739747, 2020, doi: 10.1007/s12571-020-01092-1. 